\title{
THE COORDINATION OF LOCAL POLICIES FOR URBAN DEVELOPMENT AND PUBLIC TRANSPORTATION IN FOUR SWISS CITIES
}

\author{
VINCENT KAUFMANN \\ Laboratoire de Sociologie Urbaine, \\ Ecole Polytechnique Fédérale de Lausanne \\ FRITZ SAGER \\ University of Bern
}

\begin{abstract}
The present article aims at assessing the possibility for urban areas to coordinate local policies of urban development and public transportation and at explaining the differences in this achievement between urban regions. In order to do so, the study draws support from two empirical sources: a historical analysis of the "mass-production" generated by the public service sectors in the field of transport and urban development in the cities of Basel, Bern, Geneva, and Lausanne since 1950, and a series of six case studies in these four cities. The study identifies factors located both at context level regarding morphological and geographical conditions as well as institutional settings and case-specific idiosyncrasies regarding organizational structure, past policy decisions, as well as vocational cultures that determine the possibility for urban areas to meet the need for policy coordination.
\end{abstract}

$I_{\mathrm{n}}$ roblem of rising mobility and growing space needs. The more mobile society has become, past urban microcosms centralizing working, shopping, lodging, and leisure activities have increasingly spread out into the suburbs and functional differentiation has taken place. "The centre attracts the service industry. The more services concentrate in the centre, the more industries can specialize and attract people from far distances. The service industry is able to pay higher rents than residents. Land prices rise. Residents are driven out. They may still work in the city ..., but they have to find an apartment in the suburbs.... Traffic grows faster than anything else. Urban people become commuters. Part of their growing income and leisure time must be spent on longer daily travel between work, shopping, recreation, and home spaces" (Linder, 1994, p. 77). All of these transformations, regarding lifestyles as much as space morphology, constitute the nucleus of the urbanization process. The first observations of this process were described by the American urbanist Melvin Webber beginning in the 1960s. In Europe, the topic has been

Direct Correspondence to: Vincent Kaufmann, Urban Sociology and Mobility, Laboratoire de Sociologie Urbaine, Ecole Polytechnique Fédérale de Lausanne, Station 16, CH-1015 Lausanne, Switzerland. E-mail:vincent.kaufmann@epfl.ch.

JOURNAL OF URBAN AFFAIRS, Volume 28, Number 4, pages 353-373.

Copyright $\odot 2006$ Urban Affairs Association

All rights of reproduction in any form reserved.

ISSN: 0735-2166. 
354 | JOURNAL OF URBAN AFFAIRS | Vol. 28/No. 4/2006

extensively documented since the end of the 1980s in various fields, such as sociology (Bassand, Joye, \& Schuler, 1988; Gazzola, 2003; Le Galès, 2002; Remy \& Voyé, 1992; Urry, 2000), geography and urbanism (Choay, 1994; Lévy, 1999; Lofland, 1998; Thrift, 1996), and political science (Heinelt \& Kübler, 2005; Judge, Stoker, \& Wolman, 1995; Lefèvre, 1998; Sharpe, 1995; Y, 2005, 2006).

The key issue in this development is the question of mobility. The more people move to the suburbs, the more commuter traffic there is in the central city, rendering the centre less attractive for residents. Within the same logic, residents who are able financially will spread out even further, which urbanizes the suburbs. Therefore, the integration of the policies for urban development and transportation constitutes the crucial means for curbing the spread of urbanization and upholding the standards set for fighting pollution (Keeling, 1995; Newman \& Thornley, 1996; Offner, 1993; Pharoah \& Apel, 1995; Wiel, 2005). On the one hand, housing developments concentrated around areas of high public transport services implement a restrictive parking policy to check the growth of automobile traffic (Banister et al., 2000). On the other hand, an urban planning policy aims to promote "the compact city" (Jenks, Burton, \& Williams, 1996), which requires a formative public transport network to absorb the concentration of the flows naturally caused by this type of urban arrangement. This integration is ensured by coordinating the sectoral policies governing urbanization with those governing city transportation.

At the core of this need for coordination is the problem of cooperation. "The contemporary practices of administrative conjunction appear to be specifically designed to solve, to ameliorate, or at least to address issues associated with the disarticulation of the state, high jurisdictional and disciplinary fragmentation, and diminished bureaucratic capacity... The key to such cooperation is interdependence, and there are no more interdependent jurisdictions, organizations, and institutions than those that make up metropolitan areas" (Frederickson, 1999, p. 706). In the following, based on Scharpf (1994, p. 27f.) the term "coordination" will be used as a welfare-theoretic concept: "[Coordination] is considered desirable whenever the level of aggregate welfare obtained through the unilateral choices of interdependent actors is lower than the level which could be obtained through choices that are jointly considered. In other words, the term is used here to describe forms of accommodation that are more demanding than the adjustment based on mutual anticipation." This definition implies that the cooperation of the relevant actors for transport policy decisions constitutes a necessary condition for coordination.

In Switzerland, a small central European country with dense populations in its urban areas, the problems previously illustrated are greatly enhanced, due to the lack of available space. Preserving territories from urban development requires a very ambitious land-use policy.

The present article aims at assessing the possibility for urban areas to meet this need for coordination and to explain the differences between Swiss conurbations in this achievement. The following will argue that planning processes are shaped by institutional constructs, historic traditions, and community perceptions. Concretely, based on a historical analysis of the "massproduction" generated by the public service sectors in the field of transport and urban development in the four urban areas of Basle, Bern, Geneva, and Lausanne, we will argue that an interrelation between the compactness of the cities, the evolution of integration between development and transport, the scope of coordination, and the type of institutions involved in this coordination can be detected. From these observations, a set of hypotheses will be derived and discussed comparing six case studies of these four cities. The findings from the qualitative comparative analysis of the cases will then be integrated in a temporal perspective on the process of coordination by seizing both the analogies and the differences between the test cases.

In the first section, the empirical and analytical approach of the present study will be presented, consisting of a two-step comparative case study design, the choice of the respective cases, and the methodology employed. In the section that follows, the four Swiss agglomerations of Basle, Bern, 
Geneva, and Lausanne are presented in terms of spatial structure and mobility, the conceptualization of the link between urban development and transport, and the measures implemented in the four cities to coordinate this link will be examined subsequently. The article will then discuss the hypotheses for the explanation of coordination performance extracted from this comparison using six case studies focused on actual planning decisions and three lines formative to the process of coordination. The conclusion consists of a final analysis summarizing both the theoretical arguments and the empirical findings.

\section{RESEARCH DESIGN, CASE SELECTION, AND METHODOLOGY}

The empirical approach of the present study consists of a two-step comparative case study design. In the first step, the four agglomerations of Basle, Bern, Lausanne, and Geneva will be compared with respect to their achievements in terms of coordinating transport and land use. Explanations of the observed differences will be derived based on the historical analysis of the respective master plans. As for the test of these hypotheses, a second comparative case study design will be employed, this time focusing on actual decision cases in the form of six infrastructure projects marked by a need for policy coordination in the four urban areas. A comparative case study design has been employed as the actual data collection embraced "how" and "why" questions, and as little control over the events and processes that form the units of analysis could be exerted (cf. Yin, 1990, p. 1).

Following a "most similar cases" design, the four urban areas, as well as the actual decision cases, have been selected to "maximize the variance of the independent variable and to minimize the variance of the control variables" (Lijphart, 1975, p. 165). The chosen four agglomerations of Basle, Bern, Lausanne, and Geneva (cf. map 1) have the same institutional superior framework in the form of the Swiss planning, as well as political system. All are about the same size, but differ in their planning tradition. They were nevertheless selected for their contrasting features, that is, cultural make-up (German speaking as against French speaking, cf. map 2), location (cross-border or strictly national), institutional structure (degree of independence at the municipal level), urban density, and use of modes of transport. The language variable is an important factor to be taken into account in analyzing social processes in Switzerland. A standard finding in Swiss political science indicates that differences with regard to both direct democracy and administrative culture more or less coincide with the language regions. Here, the generally more participatory political institutions in the German-speaking cantons provide incentives for a more intense associational life than the French-speaking ones (Kriesi, 1996; Kriesi \& Baglioni, 2003). ${ }^{1}$

The six decision cases then regard both land-use and transport issues, varying to a great extent within their institutional and organizational characteristics. The cases were selected employing three criteria:

1. The rapidity with which decisions taken were integrated into the project;

2. The institutional levels involved in the project;

3. The instance, or lack thereof, of a cross-border dimension to the case.

Three of the cases retained are located in German-speaking Switzerland and the other three in the French-speaking region of the country. These six case studies can be grouped in pairs according to the nature of the project and the location (Table 1).

In these case studies, we focus as much on the constitution of the project, its context, and its objectives, as how various actors involved in implementing the project position themselves and interact with one another. In other words, the construction of the coordination process is explored as a system of social action. 
356 | JOURNAL OF URBAN AFFAIRS | Vol. 28/No. 4/2006

TABLE 1

Typology of the Case Studies

\begin{tabular}{llcc}
\hline & $\begin{array}{c}\text { Public transport } \\
\text { infrastructure projects }\end{array}$ & $\begin{array}{c}\text { City transfer } \\
\text { point projects }\end{array}$ & $\begin{array}{c}\text { Rapid transit } \\
\text { projects }\end{array}$ \\
\hline $\begin{array}{l}\text { German-speaking } \\
\text { Switzerland }\end{array}$ & Claragraben tram & Wankdorf complex & Basle S-Bahn green \\
$\begin{array}{l}\text { French-speaking } \\
\text { Switzerland }\end{array}$ & $\begin{array}{c}\text { Extension of the Lausanne- } \\
\text { Echalens-Bercher line }\end{array}$ & $\begin{array}{c}\text { La Praille - Bachet-de-Pesay } \\
\text { complex }\end{array}$ & $\begin{array}{c}\text { Rhône Express } \\
\text { Régional }\end{array}$ \\
\hline
\end{tabular}

The chosen methodology comprised a semidirective interview of those involved in each project. The guide used the explanations proposed following the analysis of the master plans and coordination measures in each of the cities. According to the size of the case study, the interviewees varied with respect to number (from 4 to 15) and position (both political and administrative, therefore both technical and managerial level).

Generally, while a qualitative comparison cannot be a substitute for statistical analysis when sufficient cases are available, the case study design has been considered appropriate for the purposes of the present study. The question of coordination not only regards output quality, but also procedural aspects that cannot be captured with a mere cross-sectional focus. However, while the findings from this analysis are valid for the test cases, they are not generalizable. The explorative character of the presented research must be noted as we proceed to the empirical analysis.

\section{TRANSPORT AND LAND-USE PERFORMANCE OF BASLE, BERN, LAUSANNE, AND GENEVA IN COMPARISON}

The four agglomerations of Basle, Bern, Lausanne, and Geneva are characterized by differences in the level of integration of their development and public transportation networks, which is the most important aspect of the comparison. Two indicators are used to measure this integration: the development of the areas allotted to housing and infrastructure and daily modal practices.

\section{The Development of Areas Allocated to Housing and Infrastructure}

A study of the surface areas allocated to housing and infrastructure from the early 1980s to the early 1990s in the four cities ${ }^{2}$ shows that demographic growth in Basle and Bern was more contained than in Geneva and Lausanne. ${ }^{3}$ Overall, urbanization growth rates for the two Germanspeaking cities were effectively $5.5 \%$ and $7.4 \%$, compared with $12.3 \%$ and $13.1 \%$ for the two Francophone cities (see Table 1). This result must further be weighted to reflect the fact that urban growth was higher in the two Francophone cities. For the city of Geneva, whose surface area extends into the Vaud canton, growth in the city outskirts of the areas allotted to housing and infrastructure was much higher in the section comprised within Vaud, which is probably the result of differences in urban containment policy.

An inspection of the housing and employment density in the suburbs of the four cities (Table 2) shows that density is generally higher in the two German-speaking cities. This trend is particularly noticeable in the outer suburbs. One should also note the higher density of the centers of Basle and Geneva compared to the other two cities, which probably has to do with their status as border towns. 
TABLE 2

Surface Areas for Housing and Infrastructure

\begin{tabular}{lcccr}
\hline Survey period & $\begin{array}{c}\text { Basle } \\
1982-1994\end{array}$ & $\begin{array}{c}\text { Bern } \\
1981-1993\end{array}$ & $\begin{array}{c}\text { Geneva } \\
1980-1992\end{array}$ & $\begin{array}{c}\text { Lausanne } \\
1980-1992\end{array}$ \\
\hline $\begin{array}{l}\text { Proportion of areas for housing and } \\
\text { infrastructure during the first survey }\end{array}$ & $32 \%$ & $17 \%$ & $23 \%$ & $25 \%$ \\
$\begin{array}{l}\text { Proportion of areas for housing and } \\
\quad \text { infrastructure during the second survey }\end{array}$ & $33 \%$ & $19 \%$ & $26 \%$ & $28 \%$ \\
City centre & $+1.9 \%$ & $+0.6 \%$ & $+1.4 \%$ & $+5.5 \%$ \\
$\quad$ Inner suburbs & $+4.7 \%$ & $+10.8 \%$ & $+13.5 \%$ & $+16.1 \%$ \\
$\quad \begin{array}{l}\text { Outer suburbs } \\
\text { City total }\end{array}$ & $+9.6 \%$ & $+9.9 \%$ & $+14.7 \%$ & $+14.7 \%$ \\
Density of areas for housing and infrastructure & $+5.5 \%$ & $+7.4 \%$ & $+12.3 \%$ & $+13.1 \%$ \\
$\quad$ Hsg + empl./hectare city centre & $\sim 150$ & $\sim 105$ & $\sim 200$ & $\sim 110$ \\
$\quad$ Hsg + empl./hectare inner suburbs & $\sim 55$ & $\sim 55$ & $\sim 50$ & $\sim 45$ \\
$\quad$ Hsg + empl./hectare outer suburbs & $\sim 40$ & $\sim 30$ & $\sim 15$ & $\sim 25$ \\
$\quad$ Total hsg + empl./hectare & $\sim 70$ & $\sim 65$ & $\sim 55$ & $\sim 55$ \\
\hline
\end{tabular}

aAn outlying portion of Geneva's territory is located inside the Vaud canton. In this section of the city, growth of the surface areas allocated to housing and to infrastructure is $20.1 \%$, which is more than double that of the outlying area located within the Geneva canton (growth rate of $9.8 \%$ ).

Note. hsh = housing; empl. = employment.

\section{Modal Practice in Daily Activities}

The distribution of the use of different modes of transport (Table 3) supports the observations made with respect to the growth of surface areas for housing and infrastructure. The data from the 1994 microsurvey on transportation shows that the portion of daily travel of automobile use in Bern is overall lower than in the French-speaking cities, and conversely, the portion of travel by public transport is greater in Basle and Bern.

\section{TABLE 3}

Modal Distribution of Daily Mobility in Each City (Based on the 1994 National Microsurvey of Transportation)

\begin{tabular}{lrrrr}
\hline City centre, $t=8.95^{*}$ & Basle & Bern & Geneva & Lausanne \\
\hline Walking & $34 \%$ & $33 \%$ & $37 \%$ & $35 \%$ \\
Bicycle/scooter & $14 \%$ & $10 \%$ & $8 \%$ & $8 \%$ \\
Automobile & $24 \%$ & $29 \%$ & $40 \%$ & $39 \%$ \\
Public transport & $28 \%$ & $27 \%$ & $16 \%$ & $19 \%$ \\
Inner suburbs, $t=5.24^{*}$ & & & & \\
$\quad$ Walking & $30 \%$ & $27 \%$ & $28 \%$ & $26 \%$ \\
Bicycle/scooter & $8 \%$ & $10 \%$ & $9 \%$ & $4 \%$ \\
Automobile & $42 \%$ & $44 \%$ & $50 \%$ & $59 \%$ \\
Public transport & $20 \%$ & $19 \%$ & $13 \%$ & $11 \%$ \\
Outer suburbs, $t=4.46 *$ & & & & $18 \%$ \\
$\quad$ Walking & $26 \%$ & $29 \%$ & $21 \%$ & $2 \%$ \\
Bicycle/scooter & $3 \%$ & $7 \%$ & $4 \%$ & $74 \%$ \\
Automobile & $56 \%$ & $48 \%$ & $67 \%$ & $5 \%$ \\
Public transport & $15 \%$ & $16 \%$ & $8 \%$ & $3.77 * *$ \\
$t$ by agglomeration & $5.38 *$ & $6.59 *$ & $4.40 *$ & \\
\hline
\end{tabular}

Significance: ${ }^{*} 0.001,{ }^{* *} 0.005$. 
358 | JOURNAL OF URBAN AFFAIRS | Vol. 28/No. 4/2006

If the different neighborhoods of the cities are studied, a general observation is that as one moves from the city centre to the outlying areas, use of the automobile generally increases. For example, $29 \%$ of travel in the centre of Bern uses an automobile, with this figure increasing to $48 \%$ in the outer suburbs. Although this trend is present in all four cities, its proportion and extent varies. In Geneva and Lausanne, the car is globally used to a greater extent than in the other two cities. As Geneva is the densest of the four cities, this observation indicates that there is no automatic correlation between urban density and modal practice.

The reverse trend was observed for public transport, which is used to a lesser extent as one moves away from the centre of town. While the differences between cities are less marked in the inner suburbs, huge contrasts appear when the trends in the outer suburbs areas are studied. In these areas, the car is used for $67-74 \%$ of travel in the two Francophone cities, against only $48 \%$ in Bern and $56 \%$ in Basle.

These indicators clearly show Bern and Basle as being the two cities with the most compact urbanization. The evolution of the surface areas allocated to housing and infrastructure, as well as of daily modal practice, shows that urbanization and public transport infrastructure function more effectively together in the two German-speaking cities, which is due probably partially to better coordination.

\section{INTEGRATION AND COORDINATION OF MASTER PLANS SINCE THE 1950s}

A content analysis of the master plans for town planning and transportation, as well as for institutional architecture in the four cities, first provides a brief insight into the differences observed. Four aspects are particularly salient:

\section{The Complication of the Issue}

In the 1950s, the coordination of town planning and transportation was left entirely up to the communes (or to the cantons in the case of cities like Basle and Geneva, which are also cantons), and the issues raised concerned in the fields of architecture and engineering. In all four cities studied, the problem of coordinating urban development and transportation since this era has become increasingly complex.

New fields have appeared, such as ecotoxicology, of a law established to protect the environment. Transport control engineering, which was developed to handle the pressure of increasing traffic, is another example. These domains are currently indispensable and will soon become a major consideration in urban transportation policy.

With surface areas utilized on a day-to-day basis considerably multiplied over the past 30 years due to (or through the fault of) individual appropriation of the opportunities offered by rapid transport infrastructure, geographical categories involved in development-transportation coordination have also transformed. In the 1950s, the problem was one that involved only the commune. Today, this also encompasses the city and the region.

The advent of motor vehicles in the 1960s introduced the issue of "modal choice," with new horizons for coordination between development and transportation infrastructure. This new state of affairs allows new housing developments to be built around road and/or public transport infrastructure, with each new development corresponding to a specific form of urban arrangement.

In less than 40 years, the problem has evolved from one confined to community development to involving many fields, including development, transport control engineering, and environmental services, with all the institutions requiring close horizontal and vertical collaboration. 


\section{The Need for Institutional Response}

Faced with such complexity, the institutions in all four cities chose to apply similar solutions (Y et al., 1999).

There are interdepartmental coordination commissions within the commune or cantonal service sectors in each of the four cities. The task of these commissions is to coordinate public action at the level of the commune or canton. Examples include the Cantonal Co-ordination's Conference "Space-Transport-Economy" in Bern, the Coordination's Commission for Transport Planning (Koko) in Basle, the Cantonal Consultative for land-use planning (CAT) in Geneva, and the Lausanne transportation liaison group (GTLT), in addition to the coordination of the various services comprising the public works and development departments of Lausanne.

Measures of cooperation also exist among the institutions of the four cities, but they are dependent on geographical factors (proximity of a national border, size of the commune, and canton territories) and the distribution of development tasks between commune and canton. Bern and Lausanne have urban "communities"- the "Verein Region Bern" and the "Communauté de la région lausannoise" (COREL). Although these organizations essentially operate on a horizontal basis, they do occasionally involve the canton in their work. In Basle and Bern, collaboration between the institutions of other cantons and neighboring foreign regions is much more common. Intercantonal coordination in Basle for development and transportation issues is managed by the "Nordwestschweizerische Regierungskonferenz" (intergovernmental conference of the Cantons of northwestern Switzerland), while international coordination with Germany and France is carried out by the "Regio Basiliensis." In Geneva, coordination with the Vaud canton and the French Rhone-Alps Region is ensured by the "Comité régional franco-genevois" (the French-Genevois Regional Committee).

The four cities have commissions linking the sectors of various types of institutions with associations and lobby groups (automobile clubs, touring clubs, ecological transport associations, public transport users association, company associations, etc.). One such example in Basle is the Transport Commission, which is comparable to Geneva's Traffic Circulation Consultative Commission (CCC) or Lausanne's COREL working groups.

Let us however note that two differences were observed among the cities with respect to the solutions proposed by their institutions.

The implementation of development-transport coordination commissions took place later in the two French-speaking cities. They appeared only in the wake of the restrictions brought about by the federal law on urban development, with the exception of cross-border coordination in Geneva, which happened endogenously.

In the city of Bern, ad hoc commissions are usually formed for specific projects where coordination between development and transport is required, such as the main pole of development in Bern-Wankdork. Such commissions are uncommon in Basle and nonexistent in the two Frenchspeaking cities.

\section{The Conception of Development-Transportation Integration}

We observed a difference among the four cities in the evolution of coherence between development and transport over time.

Bern and Basle witnessed their multimodal combination of automobile and public transport change to transportation based essentially on public means to meet environmental objectives. Current master plans situate new developments systematically in proximity to railway stations, with city limits designed to be attainable mainly by public transport and nonmotorized modes of transport. 
360 I JOURNAL OF URBAN AFFAIRS | Vol. 28/No. 4/2006

In Geneva and Lausanne, the city structure has transformed from being a function only to the automobile to taking into account the multimodal means of public transport, by applying solutions where various modes are able to function together. In both cities, master plans currently provide for dual access to new developments and to major districts.

These different concepts of development-transport coordination have considerably shaped the urbanization and transportation supply in the four cities studied. In Geneva and Lausanne, vast industrial areas and new housing districts have been developed with a minimum in public transportation services (bus lines), whereas in Bern and Basle, urbanization has always been developed in tandem with a dense and close-knit network of public transportation (tramways and light railways).

\section{The Scope of Coordination}

A fourth overall observation resulting from the analysis of the master illustrates the scope of coordination between development and transport. Differences among the four cities in question were also observed in this area.

In Bern and Basle, the growing complexity of the problem since the 1960s has been accompanied by increasingly close collaboration. Today, the two policy areas are integrated at the conceptual Q4 level. In Bern, the two are so closely related that they can no longer be separated.

Coordination in Geneva and Lausanne, on the other hand, is less developed today than 25 years ago. In Lausanne, the failure of the CIURL (Lausanne regional inter-city committee), which had produced an ambitious master plan in terms of development-transport integration, has coincided with a separation of the two issues. In Geneva, the dissociation of the master plans for transportation in the 1980s has hardly helped to promote coordination. Development plans are drawn up in a separate department and by a different team from those intended for transport.

\section{Synthesis}

The analysis of the master plans revealed an interrelation between the compactness of the cities, the evolution of integration between development and transport, the scope of coordination, and the type of institutions involved in this coordination (Table 4). Finally, four specific types of coordination, corresponding to the four cities, were identified in the analysis.

\section{TOWARD EXPLANATIONS}

The findings of the analysis of the master plans beginning from the 1950s and the structure of the institutions present four main ideas, which have more similarities than differences.

\section{Institutional Structure as a Regulator of Power or Action}

The differences in institutional structure observed among the cities could provide an explanation for the difference in the effectiveness and scope of the coordination observed in the master plans of the four cities (Y, 2002, 2005).

Political participation in Switzerland is not confined to voting. Direct democracy is very elaborate, particularly at the local level, and also at the cantonal and the national levels. The extent of direct democracy at the cantonal and local level varies considerably across cantons. Overall, there is a west-east divide with respect to the extent given to direct democracy, direct democracy being more extensive in German-speaking cantons (in the east), than in French-speaking cantons 
| Coordination of Local Policies | 361

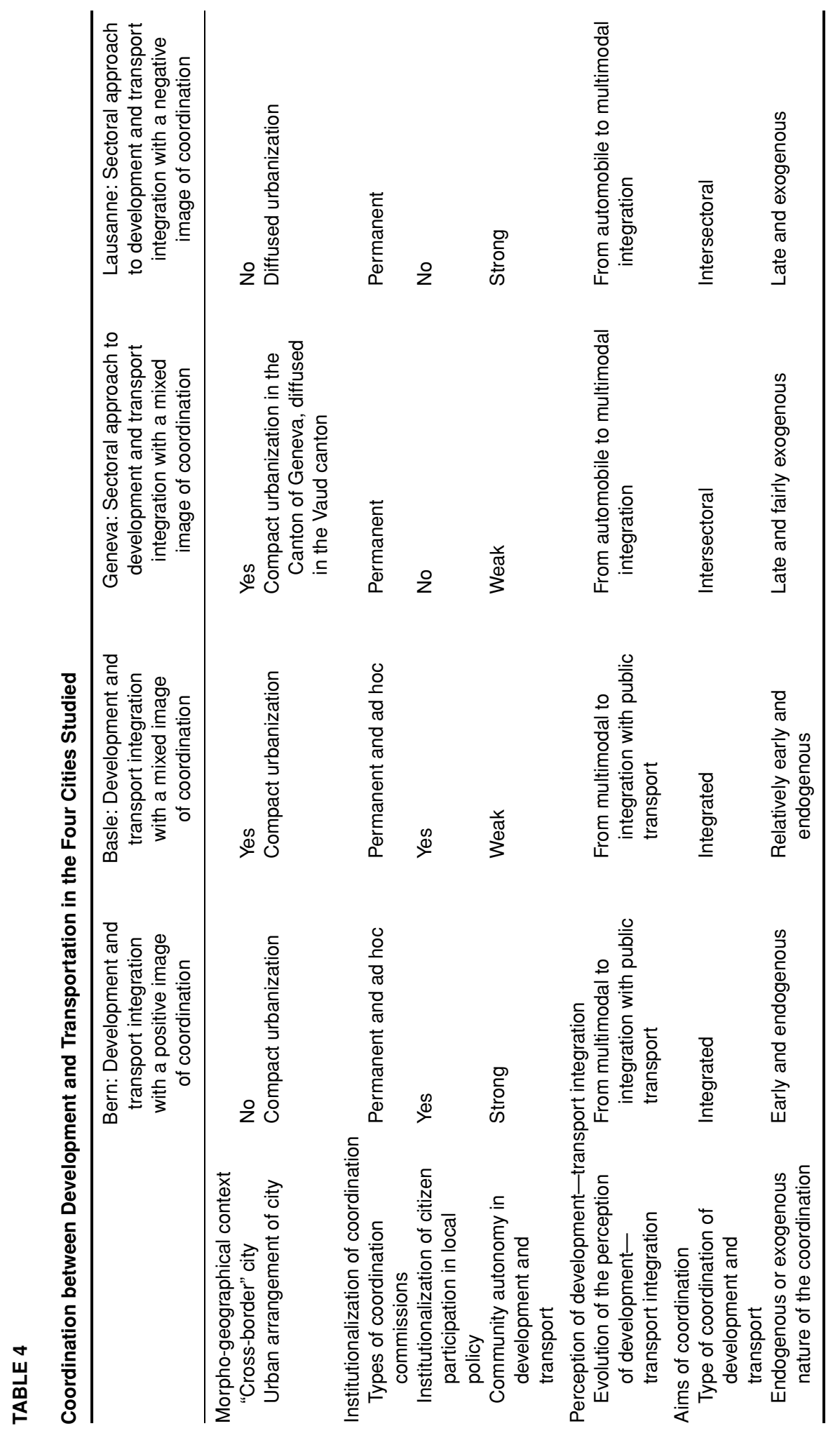


362 I JOURNAL OF URBAN AFFAIRS | Vol. 28/No. 4/2006

(in the west). However, the Swiss case also illustrates the "broken promises" (Papadopoulos, 2001) of direct democracy. Direct democracy reinforces corporatist schemes of decision making, because political parties and organized interests cooperate to minimize the risk of negative votes (Neidhart, 1970). Moreover, referendums tend to be used by groups who defend the status quo and thereby have a structurally conservative effect (Papadopoulos, 1994).

Besides strong direct democratic institutions, there are various degrees of citizen participation in Swiss cities. Joye et al. (1995) have shown in a comparison of six Swiss cities that the extent to which direct citizen participation is granted, that is, the existence of opportunity structures, has a strong effect on the state's capacity to act. In this respect, the NIMBY ("not in my backyard") phenomenon (Fischer, 1990) describing the behavior of citizens affected by a certain policy who negate both the state's right to define public objectives and policy experts to define public problems has to be mentioned. The authors conclude that a strong citizen participation at the local level helps improve living conditions with a rather domestic and neighborhood orientation, as well as a specific focus on transportation issues, while a rather representative democratic culture helps promote the city as a whole and emphasizes an exterior orientation.

Within this direct democratic and participatory context, the existence of ad hoc commissions, in particular, may enable the intersectoral approach to the development-transport problem to be transformed into an integrated, transversal approach. These commissions may notably promote dialogue among actors from different backgrounds. Furthermore, in cities where participatory democracy is very much in practice, such as Bern and Basle, they may contribute to the abandonment of the rationalities of power among public actors in favor of approaches based on action.

The presence of multiple actors stimulates the habitual play of coalitions. Ad hoc commissions are also outside the institutional structure of departments to a certain extent, which hypothetically excludes them from the sphere of the power games inherent in the public service sectors, thereby inducing a shift in the approaches involving power or action.

Conversely, permanent commissions with a strong political presence, such as those in Geneva and Lausanne, may constitute an obstacle to coordination, because they represent typical fora for the expression of approaches based on power. This first hypothesis acquires particular relevance in contexts where democracy tends to be representative. This is the case in Geneva and in Lausanne, where permanent commissions are sectoral and headed by elected representatives.

\section{Past Perceptions of Development-Transportation Integration as a Structural Opportunity for Coordination}

The legacy of the past plays an important role in public policy making (Rose, 1990; Rose \& Davies, 1994). "In terms of policy development, path dependency captures the tendency for a policy step in one direction to encourage the next step to be in a similar direction. Fundamentally, the way policies are organized influence future choices" (Gains, John, \& Stoker, 2005, p. 27). Current physical contexts thus are partially the product of past policies concerning the integration of development and transport. The size and shape of the light railway networks are especially influential, because they represent the spatial outline of a coordinated policy. How is it possible to coordinate regional development with public transport if there is no more railway infrastructure, or if such infrastructure never existed?

In the 1960s, the decade in which development-transport coordination became a topical issue with the arrival of the automobile, Geneva and Lausanne saw their tramways disappear. Today there are only $12 \mathrm{~km}$ of tram line remaining in Geneva (as compared with $175 \mathrm{~km} 30$ years ago), and the Lausanne Echalens Bercher railway is the only surviving line in Lausanne following the disappearance of the Jorat railway and the tramways during the same year as the national exhibition. These decisions are even more important, because neither Geneva nor Lausanne had 
particularly well-developed light railway lines. Master plans established from this period onward can therefore no longer link development to transportation using any infrastructure other than bus lines, having only a very limited formative impact on the shape of the territory. In Bern and Basle, on the other hand, a large section of the light railway was maintained, thus providing master plans with an existing structure for integration. This difference in physical context has influenced how coordination of development and transport has been conceived in master plans. This introduces our second basic hypothesis. In the two French-speaking cities, plans for integration must always include projects for the construction of infrastructure, as was the case in Lausanne with the CIURL master plan in 1973, or Geneva with the 1989 plan. In Bern and Basle, such planned integration can rely on existing infrastructure. Although it is not easily identifiable in the "mass-produced" reports, this physical difference most likely has an influence on the planner's perceptions and work, as well as on the policy aspects of urban development. The master plans, when studied, give the impression of being powerful determinants of the "realm of the possible," as imagined by the various actors, whether policy makers or experts.

\section{The Incentive Effect of Ecological Values}

Coordinating urbanization with public transport infrastructure implies going against the predominant social values, which make people reason in terms of accessibility by road greater than by means of public transport. This countercurrent of values is quite commonly associated with the ecological trend. Respect for the environment is more of a tradition in the cultures of the countries of northern Europe than in those of the south. As for Switzerland, public opinion between the ethno-linguistic groups for a long time has differed with respect to ecological values (Bisang \& Knoepfel, 1999, 2001). Hence, it is possible that in the two German-speaking cities the acceptance of coordination is greater at the political level than at the level involving experts. This is our third hypothesis.

If such an interpretation were confirmed by the case studies, it would help clarify the reason that the cities of Basle and Bern have remained more compact than their two French-speaking counterparts.

\section{Occupational Habits as Incentives or Obstacles}

In Switzerland, professional cultures in the area of transport and development are not necessarily coordinated on a national scale. In fact, based on the analysis of the master plans, one could interpret that this is most likely not the case. Examples are provided by how development and transport coordination is structured, or the fate of the tram lines in the 1950s and 1960s, etc. Professional references and schools of thought are linked to language as expression of different cultures, and may provide specific opportunities for coordination. In German-speaking Switzerland, the integration of urbanization and public transport infrastructure is probably facilitated by the occupational habits, or "culture," of developers and transportation engineers.

This observation can be captured using Haas' (1964) concept of "epistemic communities": "An epistemic community is a network of professionals with recognized expertise and competence in a particular domain and an authoritative claim to policy relevant knowledge within that domain or issue-area" (Haas, 1992, p. 3). This shared expertise can lead to a sectoral consensus on certain policy issues across municipal boundaries. "Presented with incomplete or ambiguous evidence, members of an epistemic community would draw similar interpretations and make similar policy conclusions. If consulted or placed in a policy making position, they would offer similar advice. Unlike an interest group, confronted with anomalous data, they would retract their advice or suspend judgment" (Haas, 1990, p. 55). 
364 | JOURNAL OF URBAN AFFAIRS | Vol. 28/No. 4/2006

However, it should be noted that the occupational cultures of engineers and developers are particular. They have no common language and are based on different ways of thinking. They can therefore constitute an important obstacle to coordination between transport and development. The presence of ad hoc coordination commissions in the two German-speaking cities has probably brought the two fields closer together by forcing them to be compatible to accomplish specific projects. This expectation forms our last hypothesis.

\section{THE PRACTICAL APPLICATION OF MASTER PLANS TO PROJECTS: SIX CASE STUDIES}

To test the hypotheses derived from the analysis of the master plans, qualitative case studies of the four cities surveyed were retained. Thus, the overall concepts and measures for coordination identified could be tested in live situations.

In the following, the cases will be shortly presented, followed by several hypotheses discussed based on the findings from the case studies and on our master plan analysis. Three lines of action Q5 formative to the planning and decision process will then be derived.

\section{Presentation of the Cases}

The objective of the case studies is to highlight the combination of rationales that guide action and construct a project involving both urban development and transportation aspects. The cases are shortly presented in the following paragraphs.

\section{Basle: The Claragraben Tram}

This project, which has been abandoned in a popular vote, consists of building a tram line that connects with a transfer point. The objective is to provide additional transportation to the city centre from the north. The impact of the project is restricted to a very narrow area where population density is high.

\section{Basle: The S-Bahn Green Line}

This project, which has been completed, consists in the provision of new, diametral rail transport using existing infrastructure. It is part of a larger project to construct an S-Bahn network in the Basle region. The green line crosses the border into France, which complicates the decisionmaking process and the measures for coordination.

\section{Bern: The Wankdorf Point}

Currently underway, plans for the project include a central city hub, comprising notably motorway access, an S-Bahn railway station, and a tramway terminus. This commuter complex is intended to house businesses, a new stadium, a shopping centre, leisure facilities, and a commuters' park-and-ride. The location of the project is presently sparsely populated, with partnerships between the public and private sectors.

\section{Geneva: The Rhône Express Regional}

This completed project's goal was to renew the light railway transport supply between the city centre and the western part of the canton of Geneva using existing infrastructure. The project, 
whose impact is regional, is located in a sparsely populated zone. The terminus of the line is situated on the French-Swiss border point of La Plaine. An extension of the line to the French city of Bellegarde is being studied, as is the intensification of urban development close to the railway stations.

\section{Geneva: The Praille-Bachet-de-Pesay Transfer Point}

This project, currently in the planning stages, redefines the entrance into the city of Geneva from the south. Located at a motorway junction and in proximity to a public transport transfer point, the project includes plans to build a stadium, a shopping centre, hotel and cultural facilities, a commuter parking lot, and a railway station. A key element is the heavy involvement of the private sector (the property developer of the stadium and shopping centre).

\section{Lausanne: The Extension of the Lausanne-Echalens-Bercher Line}

The project, currently underway, would extend a regional railway line to the city centre and develop an access point to public transportation at the new terminus. The project is situated in a densely populated area and aims to redistribute the urban concentration in Lausanne. It involves partnerships between the public and private sectors.

Table 5 reports the information found in the case studies that is relevant for the qualitative test of our hypotheses, which will be discussed subsequently.

The case studies serve to test the hypotheses already set forth, to bring out new aspects, and to highlight the social dynamics underlying the various explanations. In the following paragraphs, Table 5 will be elucidated as we will discuss the proposed explanations for coordination based on the case studies.

\section{Institutional and Organizational Structure}

The case studies demonstrated the importance to the decision-making process of institutional architecture, that is, of the internal organizational structure of public service and coordinating bodies. In this context, three elements were identified as central.

First, the precision applied when defining the roles of those involved in the project. A clear organization chart, characteristic of the Basle and Bern cases, paves the way for each actor to take charge of their own duties and to adopt a standpoint. Indeed, the three Swiss-German case studies present no duplication of duties in the ad hoc coordinating commissions, and the distinction between the political and technical aspects is clearly and formally made. This clarity also is also apparent in the Lausanne LEB and Geneva Rhône Express Régional projects. In the Praille-Bachet complex, however, decision-making powers overlap, with an apparent lack of political definition regarding the objectives pursued. The separation of negotiation from the political sphere became especially crucial for preventing power-driven processes. Because experts sought a rational policy solution rather than the maximization of relative gains for their respective community, their negotiations basically tended to be policy driven. The more policy decisions were left to experts, that is, the higher the room for maneuvering by the administration, the less competitive the coordination process will become.

Second, involving the network of project actors in the decision-making process is consequential. The case studies showed that those measures comprising "open" networks, such as those existing in the first development phase of the Basle green line, or those observed in the case of the Geneva Praille-Bachet project, encourage rationalities of power struggles over action-oriented attitudes. Because the people involved in any one project are not the same depending on the type 
366 | JOURNAL OF URBAN AFFAIRS | Vol. 28/No. 4/2006

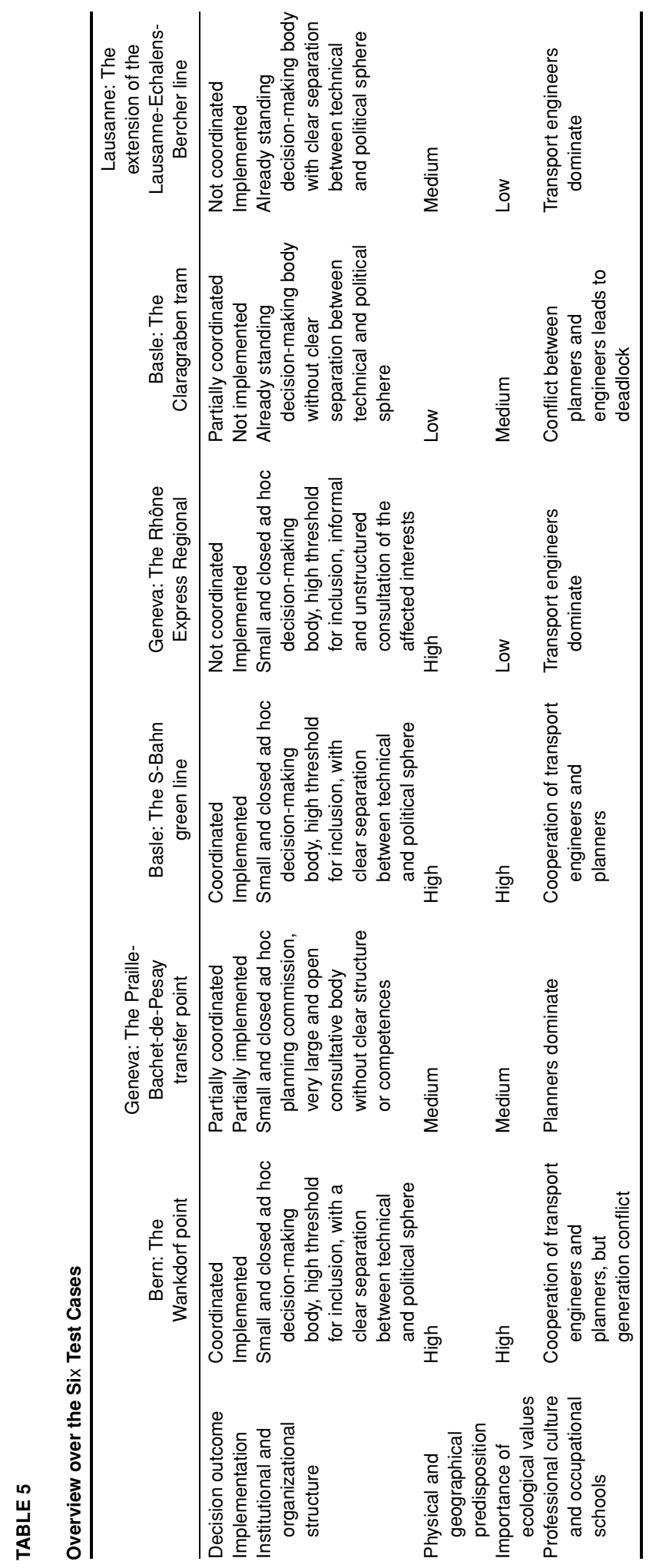


of the project, the observation about open networks made above reinforces the notion that ad hoc commissions facilitate decision making.

Third, there is a link between efficient commission work and the absence of intermediaries. Centralization facilitates coordination because there is a central transmission belt for all interactions that, on the one hand enhances the liability of the contacts because of no parallel information flows. This also enables multilateral negotiations by abridging the distance between the actors involved (Y, 2005). The analyses showed that a project with no middlemen progresses more dynamically because those involved have more freedom to act. This third element was in fact cited as a "golden rule" of coordination by several of those interviewed in the Bernese case study.

It has to highlighted, though, that these findings do not undoubtedly show that successful coordination performance at the planning level were automatically realized. On the contrary, the case of the Claragraben tram in Basle shows that a well-coordinated solution can very well be refused in a popular vote. Hence, achieving policy coordination and implementing coordinated solutions are two different affairs. However, the case studies expose, with respect to institutional factors, the organizational conditions that foster policy coordination in the planning process.

\section{Geographic Context}

The case studies also confirm the importance of the morphological and geographic context in determining how existing structures for urban development and transport integration affect coordination. In this respect, several instances proved revealing. In Geneva and Lausanne, many questioned do not believe the possibility of integrating town planning with public transport infrastructure. One Lausanne manager stated, "People choose the location of their homes in relation to motorways, and nothing will change that." To prove his point, he evoked the current housing situation in the suburbs of Lausanne and the autonomy enjoyed by the communes with respect to allocation plans. Similarly, the Praille-Bachet complex illustrates the difficulty of redirecting the development of a sector that has been built around the automobile toward multimodal accessibility. Conversely, in the Bern-Wankdorf project, the indissociability of public transport and urban development - the heritage of past policy choices — continues to influence professional schools of thought today.

\section{Ecological Values}

The case studies further confirm that ecological values are an incentive to the integration and coordination of urbanism and transport. Formalized by laws of either federal (OPair, OPB) or cantonal (Geneva law on public transportation) jurisdiction, these values were important in each of the case studies retained. The cross-border green line of the Basle S-Bahn is undoubtedly the best illustration. The idea for the project originated in Switzerland for environmental reasons. In France, at a time when environmental issues were absent from the political agenda, the project aroused little enthusiasm. In spite of this skepticism, the project was finally realized as a result of the tenacity of the Swiss partners.

\section{Professional Culture and Occupational Schools}

Three aspects of the case studies were identified as central with respect to professional cultural references.

First, within a coordination process, occupational schools of thought that vary can be an asset. This is the case in ad hoc commissions in particular, when all actors are financially involved and 
368 I JOURNAL OF URBAN AFFAIRS | Vol. 28/No. 4/2006

share the same will to succeed. In such cases, the diversity of references and working methods becomes a source of enrichment for the project. In other cases, especially where networks are very open and where leveraging for position is of the utmost importance, occupational cultures that differ are generally a source of conflict.

Second, coordination builds professional cultures or customs. In Geneva, Lausanne, and Basle, where we identified a poor "culture of coordination" between engineers and town planners, projects are anchored in either one of two fields: transportation (the LEB, Rhône Express Régional, Basle RER green line), or urban planning (the Praille-Bachet project). In such cases, the object is to cooperate with the other field. Difficulties in coordinating policies sometimes arise, as in the case of Praille-Bachet, where the locations chosen for the shopping centre, the convention centre, and the hotel restrict the options for integration with the public transport infrastructure. In other cases, this situation leads to conflict within the commissions in charge of coordination, as in the case of the Clargraben tram. In still other instances, the link with the other field failed to occur at all, as in the Rhône Express Régional project or the Basle S-Bahn green line. Neither of these projects has an urban-planning component, because the plans made in this domain were never carried out. This is contrary to Bern, where we noted a robust "culture of coordination" implemented between urban development and transport from the outset of the project.

Third, occupational culture evolves. The Bern Wankdorf case highlighted conflicts among transportation engineers: the "coordination culture" of the older members is not the same as that of the younger ones.

\section{Further Insights from the Case Studies}

In addition to these considerations, three aspects were identified in the case studies. The monographs of the master plans did not show these dimensions.

The first concerns national policies. Transportation policy is of great importance in all the case studies. The rules for the financing of infrastructure stipulated by this policy constitute a structure of opportunities seized by local actors. Several projects were financed by the Confederation in this way: the Lausanne-Echalens-Bercher extension received 40 million in support, the CISIN will provide 5 million for the stadium at Praille-Bachet, and the Claragraben tram project will receive the equivalent of $15 \%$ of the total amount invested. Other projects, on the contrary, could not be realized because of a lack of funding, such as the RER railway station originally developed in the Bernese transfer point of Wankdorf (the national railway company CFF did not want to create a precedent). In general, Swiss government policy is interpreted as an incentive for project realization, especially because their provided financial support usually comprises conditions pertaining to deadlines. The most spectacular example from this point of view is undoubtedly the LEB, where the involvement of the State not only enabled the project to be carried out, but also reopened a second project to renovate the Place du Flon, which is the new terminus of the line.

Second, the financial arrangement was identified as central to integration and coordination between urbanism and transport. Although laws that define political objectives do help projects be launched by providing them with a raison d'être, incentive laws are decisive in pushing a project through to its realization. The federal order on traffic separation illustrates this point well. Because the funding provided to projects was tied to specific conditions, certain technical solutions were allowed to be chosen over others. In the case of the LEB extension, financial support from the Confederation acted as a barrier to coordination, restricting the project to remain exclusively in the domain of transportation. More generally, financial arrangements for projects influence coordination, with the best example of this being the future stadium at La Praille-Bachet. The fact that a large part of the funding derives from the property developers of the shopping centre 
constitutes an obstacle to coordination between urbanism and transport, because the locations are a priori not modifiable.

Time also was identified as being a central issue in measuring the quality of a coordinated policy. Two examples are revealing in this area. The Rhône Express Régional in Geneva, completed in 1994, may be considered a successful case of coordination, as the decision-making process evolved smoothly and ended in the realization of the project. However, the transport supply of this project has now been called into question, because little use is made of the line in comparison with its potential service, with doubts whether the supply will continue to exist in the long term. Lack of coordination between transport supply and urbanization can therefore be problematic for the viability of the entire operation. Another contrasting example is that of Bern Wankdorf, where the nonrealization of the Wankdorf S-Bahn station could be considered as a failure, because it prevented a part of the coordinated project from being built. However, the decision not to build the station may also be considered proof of the truly coordinated nature of a project whose objective is to integrate urbanism and transport. Furthermore, the decision is not irreversible, and the station will most likely be built in the medium term.

\section{THREE LINES FORMATIVE TO THE DECISION-MAKING PROCESS}

Obviously, all of the above aspects are interdependent. They are part of a general process of either rupture or continuity, depending on the case studied. Three lines in this process were identified as formative in the relations among the actors.

\section{Line 1: From Legitimacy to Ambition}

In contexts where respect for the environment has an undeniable legitimacy, integration between urban-planning and transportation is designed to benefit public transportation, which implies taking ambitious coordination measures. In cases where environmental consciousness is little developed, however, integration between urbanism and transport is conceived to benefit roads, which implies constrained ambitions for coordination.

Several aspects are likely to promote one or the other of these choices. Political party power struggles at the local level contribute to establishing the political legitimacy of environmental concerns, occupational culture, and the morphological and geographic context, which alone will play a crucial role in determining the potential for integration between urbanism and transport. These elements will thus shape the degree of involvement of the various actors, which will subsequently define the quality of the operational measures implemented.

\section{Line 2: From Power Struggles to Action}

The studies identified two approaches to decision making, affecting either different phases of the project or the whole process: (a) an approach where the actors confront one another in a power struggle, seeking recognition or even an affirmation of supremacy; and (b) an approach where actors cooperate with a view for action, with the goal being the realization of the project, even at the cost of compromise.

Several aspects may facilitate the adoption of one of these approaches over the other. Sharing the same values and objectives, particularly with respect to the environment, clearness of the internal institutional architecture of public services, a restricted network of actors including only those directly involved, and the possibility of benefiting from national funding will all promote an actionoriented approach. On the contrary, weak legitimacy for environmental concerns, convoluted 
370 I JOURNAL OF URBAN AFFAIRS | Vol. 28/No. 4/2006

institutional architecture, an open network of actors, and sectorally divided occupational cultural habits will create favorable conditions for a power-driven approach.

\section{Line 3: From Ambition and Action to the Project}

The extent of the ambition of those involved and an approach based on action are not enough to guarantee a well-coordinated project. Therefore, the third line becomes greatly significant. For effective coordination to be ensured, ambition and the will for action must be backed by a legislative framework. Master plans, laws, and financing to provide opportunities for coordinated projects must particularly take place. In this context, the report entitled "Bernese RER and Urbanisation" was decisive in making the exemplary coordination observed in Bern possible.

With respect to legislature, no incentive law exists for coordination at the federal level, nor at the level of the cantons. Therefore, coordination is currently more of an obstacle to the financing of a project than an asset. The extension of the LEB demonstrates this, because the opportunities for federal financing of this project originate in the law on railways. The project must therefore imperatively remain within this sector to benefit from federal support.

\section{The Differences among the Cities}

These three lines illustrate the differences observed among the cities in terms of integration of urban planning and transportation, and of coordination of the relevant policies.

The ambitions for coordination observed in French-speaking Switzerland were more limited than those observed in the German-speaking parts of the country. This is the result of differences in the degree of legitimacy given to environmental concerns and designs more or less oriented toward road accessibility. These situations are in turn the product of visions brought about by the policies adopted in the past with respect to the integration of urbanism and transport.

In the Basle Claragraben and French-speaking cases, goals for transport-urban policy coordination are apparently not defined prior to the start of the project. This results in a situation where coordination measures are implemented at the same time as the objectives for coordination are being defined during project realization. The Wankdorf and Basle green line projects, on the contrary, are the result of predefined objectives, shared by all those involved (with the exception of the Alsatian Region in the case of the S-Bahn green line). Coordination here is oriented toward action.

Finally, the depth of ambition to bring about coordination and the dominant approach to integration contribute to the appropriation of the various opportunities for the implantation of a project. Thus, it is possible to differentiate between those cases where the opportunities taken stem from master plans. Opportunities essentially financial are linked to the state. The most ambitious projects fall into the first category, with examples being Bern Wankdorf, the Basle S-Bahn green line, and the Geneva Rhône Express Régional project (which is part of the Public Transport 2005 project, but is nonetheless void of any stipulations for the integration of urbanization and public transport infrastructures). Examples of projects having used external financing opportunities include the LEB extension (Lausanne), the Praille-Bachet point, and the Claragraben tramway (Basle).

\section{CONCLUSION}

Coordination between urban development and regional city transportation policies is necessary. It is not, however, sufficient to ensure good integration between urban development and public 
transport infrastructure. In summary, this is the main conclusion drawn following the analysis of the master plans and other overall schemes in the four cities studied.

The coordination of public policies cannot be measured only in terms of goals. In the introduction, we detailed the objectives in Swiss laws relating to land conservation and antipollution that comprise stipulations on the integration of urban development and public transport infrastructure, requiring the effective coordination of the sectoral policies concerned. However, the analyses show that the application of the national laws on environmental protection and urban planning, which come under the jurisdiction of the cantons, is weighted at the local level by other concerns.

Two elements illustrate this notion. First, the conceptualization of the link between development and the transportation networks varies. In Basle and particularly Bern, this link is conceived to construct a city centered on public transport access, while in Geneva and Lausanne, the link focuses on both public and private vehicle access. Secondly, the degree of ambition to realize this coordination is contrasting. This is more evident in cases where public transport integration is perceived as a priority. In this respect, it cannot be concluded that coordination is better served in the two Swiss-German cities, because the objectives and ambitions differ from one city to another.

It can be concluded, however, that coordination measures implemented to provide the development-transport interface in the four cities studied, although somewhat similar, only acquire meaning in the context of the projects they are intended to realize. The analyses highlighted that ecological awareness, past policies, occupational culture, and local political customs are potential causes of the differences observed in the conceptualization of the link between development and transport in the master plans of the four cities. Therefore, conceptual coordination is not only the product of endogenous factors, but also the result of factors exogenous to the coordination measures.

Coordination thus cannot be reduced to a function of institutional architecture and configuration of the networks of actors involved. Balancing the tension between the required openness and necessary closeness of policy networks indeed constitutes the core issue of coordination. The found multi-actor context did not foreclose coordination and instead has lead to coordinated spatial policies thanks to the openness of the decision-making process. The real problem, however, resides in the implementation of the policies decided upon, where insufficient closeness of the process often resulted in politically motivated vetoes during the implementation process. Realizing coordinated spatial solutions in Swiss urban areas often appear essentially as a constant struggle for a level of closeness sufficient for a minimal capacity to act with a regional scope. In this sense, it is not network openness that is under threat in coordination processes, but rather a minimum of network closeness that still needs to be attained. Due to widespread resistance against attempts of curtailing citizens' rights (Linder, 1994, p. 137), extensive direct democracy will also continue to be a central feature of local policy making in Switzerland. "If anything, there is more of a democracy overload rather than a legitimacy deficit" ( $Z$ et al., 2005, p. 183).

Hence, there is a need for further research integrating even more explanatory variables for the analysis of spatial policy coordination in urban areas. These additional variables could sensibly regard political factors such as the decision power of the different actors, their party affiliations, the composition of the executive and the legislative bodies, as well as socioeconomic variables regarding the respective citizenry. The inclusion of such factors might lead to more detailed explanations of both the decision outcome of coordination processes and the implementation of the respective solutions.

\section{ENDNOTES}

1 German is the language of approximately $64 \%$ of the population. French is the main spoken language in six Swiss cantons that comprise about $19 \%$ of the population. The only predominantly Italian-speaking canton embraces nearly $8 \%$ of the population, while $9 \%$ of the population speaks other languages. 


\section{I JOURNAL OF URBAN AFFAIRS | Vol. 28/No. 4/2006}

2 Based on data from the Swiss Federal Office for Statistics.

3 This analysis could only be carried out for the Swiss portions of the cities; the French portions of Geneva's surface area and the French and German portions of Basle were therefore excluded.

\section{REFERENCES}

Banister, D., Stead, D., Steen, P., Akerman, J., Dreborg, K., Nijkamp, P., et al. (2000). European transport policy and sustainable mobility. London: Spon Press.

Bassand, M., Joye, D., \& Schuler, M. (1988). Les enjeux de l'urbanisation: Agglomerationsprobleme in der Schweiz. Bern, Switzerland: Peter Lang.

Bisang, K., \& Knoepfel, P. (1999). Umweltschutz: Politische Prioritäten, persönliche Einstellungen und Verhaltensweisen der Stimmberechtigten. UNIVOX Teil II Umwelt 1999. Bern/Zürich, Switzerland: GfSForschungsinstitut.

Bisang, K., \& Knoepfel, P. (2001). Umwelt: Problemwahrnehmung, Einstellungen und Verhalten im Zeitverlauf. Univox Teil II Umwelt 2000/2001. Bern/Zürich, Switzerland: GfS-Forschungsinstitut und IDHEAP.

Choay, F. (1994). Le règne de l'urbain et la mort de la ville. In J. Dethier \& A. Guiheux (Eds.), La ville, art et architecture en Europe 1870-1993. Paris: Centre George Pompidou.

Fischer, F. (1990). Technocracy and the politics of expertise. Newbury Park, CA: Sage.

Frederickson, H. G. (1999). The repositioning of American public administration. PS: Political Science \& Politics, 32, 701-711.

Gains, F., John, P. C., \& Stoker, G. (2005). Path dependency and the reform of English local government. Public Administration, 83(1), 25-45.

Gazzola, A. (2003). Trasformazioni urbane. Naples, Italy: Liguori Editore.

Haas, E. B. (1964). Beyond the nation-state: Functionalism and international organization. Stanford, CA: Stanford University Press.

Haas, P. M. (1990). Saving the Mediterranean: The politics of international environmental cooperation. New York: Columbia University Press.

Haas, P. M. (1992). Introduction: Epistemic communities and international policy coordination. International Organization, 46, 1-35.

Heinelt, H., \& Kübler, D. (Eds.) (2005). Metropolitan governance. Capacity, democracy and the dynamics of place. Oxon, NY: Routledge.

Jenks, M., Burton, E., \& Williams, K. (Eds.) (1996). The compact city—A sustainable urban form? London: E \& FN SPON.

Judge, D., Stoker, G., \& Wolman, H., (Eds.) (1995). Theories of urban politics. London/Thousand Oaks, CA/New Delhi: Sage Publications.

Keeling, D. (1995). Transport and the world city paradigm. In World cities in a world-system (pp. 115-131). Cambridge: Cambridge University Press.

Kriesi, H. (1996). Le clivage linguistique. Problèmes de comprehension netre les communautés linguistiques en Suisse. Berne, Switzerland: Federal Office for Statistics.

Kriesi, H., \& Baglioni, S. (2003). Putting local associations into their context: Preliminary results from a Swiss study of local associations. Schweizerische Zeitschrift für Politikwissenschaft, 9, 1-34.

Le Galès, P. (2002). European cities, social conflicts and governance. Oxford: Oxford University Press.

Lefèvre, C. (1998). Metropolitan government and governance in western countries: A critical review. International Journal of Urban and Regional Research, 22(1), 9-25.

Lévy, J. (1999). Le tournant géographique. Paris: Belin.

Lijphart, A. (1975). The comparable-cases strategy in comparative research. Comparative Political Studies, 8(2), $158-177$.

Linder, W. (1994). Swiss democracy. Possible solutions to conflict in multicultural societies. London: MacMillan Press.

Lofland, L. (1998). The public realm. Exploring the city's quintessential social territory. New York: Aldine de Gruyter.

Neidhart, L. (1970). Plebiszit und pluralitäre Demokratie. Bern, Switzerland: Francke. 
Newman, P., \& Thornley, A. (1996). Urban planning in Europe. London: Routledge.

Offner, J.-M. (1993). Les “effets structurants" du transport: Mythe politique, mystification scientifique. In L'espace géographique, $n^{\circ} 3$.

Papadopoulos, Y. (Ed.) (1994). Elites politiques et peuples en Suisse. Analyse des votations fédérales: 1970-1987. Lausanne, Switzerland: Réalités sociales.

Papadopoulos, Y. (1998). Démocratie directe. Paris: Economica.

Pharaoh, T., \& Apel, D. (1995). Transport concepts in European cities. Aldershot: Avebury.

Remy, J., \& Voyé, L. (1992). La ville: Vers une nouvelle definition? Paris: L'harmattan.

Rose, R. (1990). Inheritance before choice in public policy. Journal of Theoretical Politics, 2(3), 263-290.

Rose, R., \& Davies, P. L. (1994). Inheritance in public policy: Change without choice in Britain. New Haven, CT/London: Yale University Press.

Scharpf, F. W. (1997). Games real actors play. Actor-centered institutionalism in policy research. Boulder, CO/Oxford: Westview Press.

Sharpe, L. J. (1995). The government of world cities. The future of the metro model. London: Wiley.

Thrift, N. (1996). Spatial formations. London: Sage.

Urry, J. (2000). Sociology beyond societies. London: Routledge.

Wiel, M. (2005). Ville et mobilité: Un couple infernal? La Tour d'Aigues: Editions de l'aube.

Yin, R. K. (1990). Case study research. Design and methods. Thousand Oaks, CA: Sage Publications. $X$ (2000).

$X$ et al. (2003).

$\mathrm{Y}(2002,2005,2006)$.

$\mathrm{Y}$ et al. (1999).

$\mathrm{Z}$ et al. (2005). 


\section{Queries}

Q1 Author: References 'Scharpf, 1994'; 'Papadopoulos, 2001'; 'Joye et al., 1995' are not included in the reference list. Please check.

Q2 Author: Maps 1 and 2 have not been provided in the article. Please check.

Q3 Author: Reference 'Kriesi et al., 1996' has been changed to 'Kriesi, 1996' as per the reference list. Please check.

Q4 Author: The sentence "In Bern and Basle, the growing complexity ..." is not clear, Please check.

Q5 Author: Please check whether the change retains the intended meaning in the sentence "In the following, the cases will be...".

Q6 Author: Please spell out 'CISIN' and 'CFF', if necessary.

Q7 Author: Please spell out 'E \& FN SPON', if necessary in reference 'Jenks et al., 1996'.

Q8 Author: Please check author names in reference 'Judge et al., 1995'.

Q9 Author: Please provide the names of the editors and state/country in reference 'Keeling 1995'.

Q10 Author: Please provide the name of the state/country in reference 'Le Galès, 2002'.

Q11 Author: Please provide complete information in reference 'Offner 1993'.

Q12 Author: Reference 'Papadopoulos 1998'; 'Scharpf, 1997'; 'X, 2000'; and 'X, 2003' are not cited. Please check.

Q13 Author: Please provide state in reference 'Pharaoh and Apel, 1995'.

Q14 Author: Please provide state/country in reference 'Scharpf 1997'.

Q15 Author: Please provide state/country in reference 'Wiel 2005'.

Q16 Author: Please provide complete information in references 'X, 2000'; 'X et al. 2003'; 'Y, 2002, 2005, 2006'; 'Y et al., 1999'; and ' $Z$ et al., 2005'. 